\title{
THE ROLE OF VIDEO CONFERENCING IN FOREIGN LANGUAGE LEARNING AMONG YOUNG STUDENTS
}

\author{
Branko Medic, M.Sc., D.Sc. \\ College of Vocational Sciences in Subotica, Republic of Serbia
}

\begin{abstract}
During the coronavirus pandemic research on video conferencing effects on young language learners is more than ever relevant. During the sharp transition, educators need to fully understand the benefits and possible pitfalls of video conferencing, but also overcome resistance to change through knowledge. As author Philip Pullman rightly points out, "You cannot change what you are, only what you do." This article summarised key research and provided evidence for and against the use of video conferencing in foreign language education. Thus, it gives food for thought and reflection, as well as directions for possible interventions. However, the research was limited in terms of time and available literature, and the topic certainly requires more attention. In future, it is recommended to further research the use of multimodal interactions (sound, audio, text) in video conferencing, as well as coping strategies for dealing with the lack of interaction in the video conferencing-enabled classroom.
\end{abstract}

\section{Personal context \\ With advancements of technology and the rise of the Internet, an increasing number of educational organisations deliver courses online (Klibanov, et al., 2018). Even before the coronavirus pandemic in 2020 , almost $20 \%$ of US students have taken one or more of their undergraduate modules remotely (National Center for Educational statistics, 2018). Along with wikis and blogs, video conferencing is a popular and well-established method for online education, as it has been around for more than 50 years (Roth, Pierce and Brewer, 2020). Then 2020 came, when remote education with video conferencing became "the basic global mode of course delivery". So, "the quality of this delivery is essential" (Fatani, 2020, p. 1). \\ This sharp shift provoked a personal interest in the impact that technology-assisted tutoring has and will increasingly have on young learners. Are they "digital natives" who embrace and prefer web- conferencing tools, or they would still opt for the}

traditional classroom? The research puzzle involves multiple educational and psychological aspects. When comparing video conferencing with traditional tutoring, there are inevitable differences in student's attitudes, satisfaction, learning strategies and outcomes. It is personally intriguing to trace these effects, and reflect on the impact of technology on our personal and professional lives.

From the perspective of foreign language professionals, understanding the effects that video conferencing has on youngsters is pivotal. It is the tutor's role to facilitate the best possible learning outcomes by interacting with distant audiences, engaging and motivating them. During the COVID19 pandemic most professionals had to move away from face-to-face teaching. However, teachers, just like everyone else, are reluctant to change. The majority reported resistance to web conferencing instruction, and only $9 \%$ of academics actually prefer teaching online (Educause, 2017). Much of these negative attitudes come from lack of knowledge and understanding. Therefore, for practitioners is of utmost importance to take a closer look at video conferencing tutoring, how it works and how it impacts young language learners.

\begin{abstract}
A Review of Available Sources
Video conferencing can be defined as "synchronous audio and video communication through computer and telephone networks between two or more geographically dispersed sites" (Lawson, et al., 2010, p. 295). There are various terms, used to describe video conferencing, including web conferencing and synchronous online environment (Kear, et al., 2012). Kear, et al. (2012) suggest that web conferencing is the broader term, as it supports a wide range of communication modes. Specifically, video conferencing involves audio, video and chat (Ciekanski and Chanier, 2008). For some (Roth, Pierce and Brewer, 2020) videoconferencing is an older form to deliver distance education.

Indeed, video conferencing was introduced in 1968 (Candarli and Yuksel, 2012), and it still offers immense opportunities to improve remote education at an accessible cost (Rehn, Maor and McConney,
\end{abstract}


2016). Most notably, educators benefit from connecting geographically dispersed audiences and improved interaction (Rehn, Maor and McConney, 2016). On the other hand, learners enhance their motivation and positive attitudes building (Jauregui, et al., 2012), due to the perceived proximity and increased speed of communication in video conferencing environments (Yamada and Akahori, 2009). Overall, language learners have more opportunities to practice the target language and improve communicative competence (Vurdien, 2019).

Still, there is limited data on the actual success of distance education (Klibanov, et al., 2018). Video conferencing can even be disadvantageous for students, since multiple communication means can burden them with high cognitive load (Chandler and Sweller, 1991). Nevertheless, such observations could well be outdated. In 2001, Prensky introduced the term "digital natives", suggesting that young learners were born immersed in technology and are thus inherently comfortable with it. While the related multitasking and limited attention span might have negative impact on educational outcomes, technology is integrated in students' social and personal lives. It only makes sense to use it in education (Judd, 2018). In the next sections, the impact of videoconferencing on young language learners will be discussed in more detail.

\section{A. 2.1. Impact of video conferencing on learners' attitudes and satisfaction}

A number of studies have documented students' predisposition to offline classes, in comparison to video conferencing tutoring. For example, in 2008 Doggett reports that $80 \%$ of learners would be more comfortable in traditional classroom settings, compared to the virtual classroom. Additionally, nearly $60 \%$ agreed that video conferencing creates barriers for communication with the instructor (Doggett, 2008).

On the other hand, Candarli and Yuksel (2012) specifically focused on language learners, who participated in video conferencing lectures with a native speaker. Overall, participants reported favourable attitudes towards online sessions. $64 \%$ confirmed that the video conferencing class was beneficial for language learning. Unlike Doggett (2008), Candarli and Yuksel (2012) found a positive effect of video conferencing on interaction for $70 \%$ of students, or as one interviewee put it, "Interacting with a native speaker is the best thing. I think that kind of experience motivated me for my profession" (p. 359). Mixed findings are rather unsurprising, given the specifics of language learning. Particularly, oral language proficiency can greatly benefit from technological developments (Qian, 2009). More recently, Nakatsuhara, et al. (2019) suggest that video conferencing is viable mode for language test-taking. However, students' attitudes are impacted by quality of sound and transmission during the online test. In the last year, the COVID-19 pandemic put videoconferencing in the forefront, as it became the only possible mode of education for many. Young students were not only forced to change their habits, but also faced stressors and unknowns in every aspect of life. Indeed, there is some evidence on learners' anxiety toward the virtual classroom in comparison to offline classes (Unger and Meiran, 2020). The coronavirus crisis certainly amplified the issue. Research reported an overwhelmingly negative attitudes of students towards shifting completely to online learning. $62 \%$ confirm that they are anxious towards the transition (Unger and Meiran, 2020). Students are mostly worried about their educational outcomes, lowered learning ability and lack of faceto-face interaction (Unger and Meiran, 2020).

In the end, however, students might well be pleasantly surprised by video conferencing education. Interestingly, the survey of Fatani (2020) on 162 medical undergraduates demonstrates exceptionally high satisfaction (82\%) among participants. Likewise, Amin and Sundari (2020) studied satisfaction and attitudes among language learners during the COVID-19 pandemic. They focused on a specific tools, such as. Cisco WebEx Meeting for video conferencing. They also found great satisfaction in terms of language learning potential (among $76 \%$ of participants), meaning focus $(80 \%)$ practicality $(74 \%)$, positive impact (73\%). However, in comparison to the learning management system (LMS) Google Classrooms, scores in all dimensions were lower (Amin and Sundari, 2020). Perhaps the key reason is the greater multimodality of the LMS. Nevertheless, more recent research shows a positive agreement among young students that video conferencing is beneficial for learning, especially when it comes to foreign languages.

\section{B. 2.2. Impact on learning strategies and} communicative competence

Technological advancements promote changes in the educational paradigm and most notably - transition from the traditional tutor-centred approach to the socalled learner-centered education. As the name implies, this perspective considers the needs and specifics of learners, who take an active role in the educational process (Quintana, et al., 2013). Evidence shows that video conferencing effectively facilitates a collaborative learning strategy, even when parties are physically separated. Collaborative learning (or when students work with peers relatively independently of the instructor to acquire new knowledge) supports cognitive processes and facilitates social interaction (Ertl, Fischer and Mandl, 2006). 
Moreover, findings provided by Doggett (2008) reveal that for half of students, video conferencing encourages independent learning. For some scholars learners' autonomy is a key factor that underpins success (e.g. Yap, Neo and Neo, 2016; McCombs, 2015). It contributes to comprehension and motivation, because courses enabled through video conferencing can be more interesting and enjoyable, but also because "I don't have to worry if I am slow in learning.", as one student noted (Yap, Neo and Neo, 2016, p. 273). In language education, when pupils are active and take responsibility, they are able to set their own goals and evaluate their development (Holec, 1981).

Independent learning encourages out-of-class activities, and according to Vurdien (2019) video conferencing improves young students' communicative competence in terms of speaking skills and lexical resource. Likewise, Yamada's (2009) work revealed that video conferencing develops young people's practical skills in speaking foreign languages. For example, they learn when it is appropriate to nod or laugh in the other language (Yamada, 2009). Both verbal and non-verbal language competence is improved because students are motivated to gain knowledge (Yamada, 2009; Vurdien, 2019). Warni, et al. (2018) also concluded that technology used outside the classroom has a positive impact on autonomy and comprehension skills.

The crucial role of technology is again highlighted for learner-centred activities in the video conferencing environment (Whyte, 2011). Effectiveness greatly depends on broadband connection, video and sound, but also on instructors' skills to effectively use the technological affordances of the video conferencing platform (Whyte, 2011).

\section{2.3. Impact on learning outcomes}

When it comes to learning outcomes, findings are mixed. On the one hand, scholars like Roth, Pierce and Brewer (2020) reported lower academic grades for those whose education was entirely delivered through videoconferencing. On the other hand, Vurdien (2019), who studied video conferencing in out-of-class activities, suggested that participants in such incentives outperform those who only interact in face-to-face physical classes. Ambiguity is inevitable. Video conferencing practices can vary widely with respect to techniques, individual student attitudes, motivation, and technology use. It might be concluded, that in distance education, the medium itself stimulates learners to spend more time, engaged in foreign languages (Blake, 2011). If used appropriately, video conferencing has the potential to greatly improve learning outcomes.

\section{Raised awareness and possible repositioning}

So far, it was established that studies produce mixed findings. Many, but not all young learners are found to be comfortable with video conferencing. Negative attitudes are highly likely when remote language learning is imposed by COVID-10 and the related lockdown and compulsory social distancing measures. However, oral-visual interaction is crucial for remote education, especially during the coronavirus pandemic, as it reduces feelings of isolation and enables community building (Wang, 2014). Additionally, in the language learning context, video conferencing offers valuable benefits in terms of authentic experiences, improved psycholinguistic and sociocultural communication skills, independence, and enhanced engagement and motivation. Overall, despite the natural resistance to change, pupils, as well as tutors, might be pleasantly surprised with video conferencing lectures, and report high levels of satisfaction with this mode of foreign language tutoring.

To summarise, findings from the literature review suggest undeniable benefits of video conferencing for foreign language tutors. However, it cannot be concluded that "digital natives" will readily embrace this distance education mode, just because "the net generation" are seasoned users of technology (Prensky, 2001). It is not enough to use video conferencing for remote language tutoring. It is much more important to use it in an appropriate and insightful manner, to make the most of video conferencing instruction and avoid turning it into a disadvantageous practice. In the next section, possible interventions are suggested.

\section{Possible Interventions}

First, a reoccurring theme in literature is the disruption that technological issues cause (Ertl, Fischer and Mandl, 2006; Whyte, 2011). In fact, failure of educational activities seldom relates to students' language skills (Whyte, 2011). Effectiveness lies in the speed of broadband connection and the transmission of video and sound, but also in the tutor's skills to make use of video conferencing features (Whyte, 2011). Video conferencing can also constrain collaboration and comprehension. It goes without saying that in language courses the medium is also content, i.e. language (Hampel and Stickler, 2012). Therefore, the quality of the medium is pivotal of the right comprehension of foreign languages.

Whyte (2011) identifies one crucial factor: quality of audio transmission. Hampel and Stickler (2012) also confirm the importance of sound, as data from their virtual classroom observation indicated frequent mentions of audio problems. The scholars make a recommendation for practitioners to always be aware on the affordances of the video conferencing platform 
they are using. For example, tutors need to know whether the audio makes it possible for several people to speak at a time, or for one only (Hampel and Stickler, 2012). Additionally, problems with video are also common, especially when many parties are involved. Often the screen can "freeze" and participants cannot see each other (Lim and Pyun, 2016). Video is important to transmit body language, and its use decreases language anxiety (Hampel and Stickler, 2012).

Even with good connection and sound preparation, technical problems might take place. When this happens, solving strategies are important. The instructor can invite participants to utilise whatever available modes of communication, such as text chat (Lim and Pyun, 2016).

Second, literature suggests a link between video conferencing and leaner-centred education (e.g. Doggett, 2008; Lim and Pyun, 2016). A possible intervention for practitioners is stimulating active learning in video conferencing classes. Among the benefits of active learning are longer lasting knowledge, enhanced comprehension, analysis and synthesis, improved motivation (Yap, Neo and Neo, 2016; McCombs, 2015). Moreover, student retention rates are maximised when learners take an active part in the educational process, e.g. through demonstrations, discussions, practical doing and even teaching others (ESU, 2010). McCombs (2015) suggests five domains for effective learner-centred practices: building a positive video conferencing environment, adapting to class needs, facilitating the learner-centred process, giving personal responsibility, and providing for social needs.

Research certainly suggests more possible interventions, which are discarded in this paper as they are likely not applicable for most practitioners. For example, Vurdien (2019) recommends the use of out-of-class technology-enabled language activities. Although beneficial, these are often outside instructor's scope and control. Another stream of literature is focused on technological advancements to update basic video conferencing. Blyth (2017) highlights the benefits of immersive technologies for online language learning, and examples are augmented and assisted reality. However, emerging technologies are likely to result in even more technical issues, as AR or VR are not wellestablished. Most tutors and students likely lack the technological infrastructure to support such systems, which will likely make foreign language education less accessible.

\section{Conclusion}

During the coronavirus pandemic research on video conferencing effects on young language learners is more than ever relevant. During the sharp transition, educators need to fully understand the benefits and possible pitfalls of video conferencing, but also overcome resistance to change through knowledge. As author Philip Pullman rightly points out, "You cannot change what you are, only what you do." This article summarised key research and provided evidence for and against the use of video conferencing in foreign language education. Thus, it gives food for thought and reflection, as well as directions for possible interventions. However, the research was limited in terms of time and available literature, and the topic certainly requires more attention. In future, it is recommended to further research the use of multimodal interactions (sound, audio, text) in video conferencing, as well as coping strategies for dealing with the lack of interaction in the video conferencing-enabled classroom.

\section{References}

1. Amin, F. M., \& Sundari, H. (2020). EFL students' preferences on digital platforms during emergency remote teaching: Video Conference, LMS, or Messenger Application?. Studies in English Language and Education, 7(2), 362378.

2. Blake, R. J. (2011). Current trends in online language learning. Annual review of applied linguistics, 31(1), 19-35.

3. Blyth, C. (2018). Immersive technologies and language learning. Foreign Language Annals, 51(1), 225-232.

4. Candarli, D., \& Yuksel, H. G. (2012). Students' perceptions of video-conferencing in the classrooms in higher education. Procedia-Social and Behavioral Sciences, 47, 357-361.

5. Chandler, P., \& Sweller, J. (1991). Cognitive load theory and the format of instruction. Cognition and Instruction, 8(4), 293-332.

6. Ciekanski, M., \& Chanier, T. (2008). Developing online multimodal verbal communication to enhance the writing process in an audio-graphic conferencing environment. ReCALL, 20(2), 162-182.

7. Doggett, D., \& Mark, A. (2008). The videoconferencing classroom: What do students think?. Architectural and Manufacturing Sciences Faculty Publications, 3.

8. Educause (2017). ECAR Study of Faculty and Information Technology, 2017. Available from https://library.educause.edu//media/files/library/2017/10/facultyitstudy2017. pdf

9. Ertl, B., Fischer, F., \& Mandl, H. (2006). Conceptual and socio-cognitive support for collaborative learning in videoconferencing environments. Computers \& Education, 47(3), 298-315.

10. Fatani, T. H. (2020). Student satisfaction with videoconferencing teaching quality during the COVID-19 pandemic. BMC Medical Education, 20(1), 1-8. 
11. Hampel, R., \& Stickler, U. (2012). The use of videoconferencing to support multimodal interaction in an online language classroom. ReCALL, 24(2), 116-137.

12. Holec, H. (1981). Autonomy and foreign language learning. Oxford: Pergamon.

13. Jauregi, K., de Graaff, R., van den Bergh, H., \& Kriz, M. (2012). Native-non- native speaker interactions through video-web communication: a clue for enhancing motivation?. Computer Assisted Language Learning, 25(1), 1- 19.

14. Judd, T. (2018). The rise and fall (?) of the digital natives. Australasian Journal of Educational Technology, 34(5).

15. Kear, K., Chetwynd, F., Williams, J., \& Donelan, H. (2012). Web conferencing for synchronous online tutorials: Perspectives of tutors using a new medium. Computers \& Education, 58(3), 953-963.

16. Klibanov, O. M., Dolder, C., Anderson, K., Kehr, H. A., \& Woods, J. A. (2018). Impact of distance education via interactive videoconferencing on students' course performance and satisfaction. Advances in physiology education, 42(1), 21-25.

17. Lawson, T., Comber, C., Gage, J. \& CullumHanshaw, A. (2010). Images of the future for education? Videoconferencing: a literature review. Technology, Pedagogy and Education, 19 (3), 295-314.

18. Lim, B. J., \& Pyun, D. O. (2019). Korean foreign language learning: Videoconferencing with native speakers. In Computer-Assisted language learning: Concepts, methodologies, tools, and applications (pp. 1123-1146). IGI Global.

19. McCombs, B. (2015). Learner-centered online instruction. New Directions for teaching and learning, 2015(144), 57-71.

20. Nakatsuhara, F., Inoue, C., Berry, V., \& Galaczi, E. (2017). Exploring the use of videoconferencing technology in the assessment of spoken language: A mixed-methods study. Language Assessment Quarterly, 14(1), 1-18.

21. National Center for Educational Statistics. (2018). Fast facts: Distance learning. Available from https://nces.ed.gov/fastfacts/display.asp?id=80.

22. Prensky, M. (2001). Digital natives, digital immigrants part 1. On the Horizon, 9(5), 1-6.

23. Quintana, C., Krajcik, J., Soloway, E., Fishman, L. C. D. I. B., \& O'Connor-Divelbiss, S. (2013, April). Exploring a structured definition for learner-centered design. In Fourth international conference of the learning sciences (pp. 256263). Chicago

24. Rehn, N., Maor, D., \& McConney, A. (2016). Investigating teacher presence in courses using synchronous videoconferencing. Distance Education, 37(3), 302-316.
25. Roth, J. J., Pierce, M., \& Brewer, S. (2020). Performance and satisfaction of resident and distance students in videoconference courses. Journal of Criminal Justice Education, 31(2), 296-310.

26. The European Students' Union (ESU) (2010). Student-centred learning. Toolkit for students, staff and higher education institutions. Available from

https://files.eric.ed.gov/fulltext/ED539501.pdf

27. Unger, S., \& Meiran, W. R. (2020). Student attitudes towards online education during the COVID-19 viral outbreak of 2020: Distance learning in a time of social distance. International Journal of Technology in Education and Science (IJTES), 4(4), 256-266.

28. Vurdien, R. (2019). Videoconferencing: Developing students' communicative competence. Journal of Foreign Language Education and Technology, 4(2), 269-298.

29. Wang, Y. (2004). Supporting synchronous distance language learning with desktop videoconferencing. Language Learning \& Technology, 8(3), 90-121.

30. Warni, S., Aziz, T. A., \& Febriawan, D. (2018). The use of technology in English as a foreign language learning outside the classroom: An insight into learner autonomy. LLT Journal, 21(2), 148-56.

31. Whyte, S. (2011). Learning to teach with videoconferencing in primary foreign language classrooms. ReCALL: the Journal of EUROCALL, 23(3), 271.

32. Yamada, M. (2009). The role of social presence in learner-centered communicative language learning using synchronous computer-mediated communication: Experimental study. Computers and Education, 52, 820-833.

33. Yamada, M., \& Akahori, K. (2007). An analysis of the relationship between presence, consciousness and performance in learnercentered communicative learning using SCMC. The Journal of Asia TEFL, 4(4), 59-91.

34. Yap, W. L., Neo, M. and Neo, T. K. (2016). Learner-Centred Teaching Contributes in Promising Results in Improving Learner Understanding and Motivation: A Case Study at Malaysia Tertiary Education. Electronic Journal of e-Learning, 14(4), 266-281. 